\title{
Development of an angiogenesis-focused cDNA chip and validation of its functionality
}

\author{
Joong Sup Shim ${ }^{1}$, Hae Kwang Lee ${ }^{2}$, \\ Hyo Mi Park ${ }^{1}$, Jong Ok Kim², \\ Eun Kyung $\mathrm{Kim}^{2}$, Kyung Hoon Hwang', \\ Ki Tae Kim², Seong-Whan Park ${ }^{2}$, \\ Je Hyeon $\mathrm{Lee}^{2}$ and Ho Jeong Kwon ${ }^{1,3}$
}

${ }^{1}$ Chemical Genomics National Research Laboratory

Department of Bioscience and Biotechnology

Institute of Bioscience, Sejong University

98 Kunja-dong, Kwangjin-gu

Seoul 143-747, Korea

${ }^{2}$ Research and Development Center

Takara Korea Biomedical Inc.

Biotechnology Community-Bio 21

66-2, Sangdaewon-dong, Jungwon-gu

Seongnam 462-120, Korea

${ }^{3}$ Corresponding author: Tel, 82-2-3408-3640;

Fax, 82-2-3408-3334; E-mail, kwonhj@sejong.ac.kr

Accepted 30 June 2005

Abbreviation: bFGF, basic fibroblast growth factor; Flt1, fms-related tyrosine kinase 1; HDAC, histone deacetylase; HIF-1 $\alpha$, hypoxia inducible factor-1 $\alpha$; INK, cyclin dependent kinase inhibitor; MMP, matrix metalloproteinase; STAT3, signal transducer and activator of transcription 3; TSA, trichostatin A; TSP, thrombospondin; UPAR, human urokinase-type plasminogen activator receptor; VHL, von Hippel-Lindau

\footnotetext{
Abstract

DNA chip has been used as a powerful tool to study the genetic reprogramming of cells and its link to cellular phenotype such as angiogenesis. To evalu ate the angiogenesis related genetic reprogramming more efficiently, we here developed an angiogenesis-focused cDNA chip containing 153 angioge nesis related genes arrayed in duplicate on a slide glass. In order to validate the functionality of the angiogenesis-focused cDNA chip, we examined gene expression profiles in HT1080 cells treated with either fetal bovine serum, a well known pro-angiogenic factor, or trichostatin A, a known angiogenesis inhibitor, using the cDNA chip. All duplicate data from the analysis are well matched with each other and gene expression profiles are well consistent with
}

previously reported data. These results demonstrate that the angiogenesis-focused cDNA chip developed here can be a useful tool towards angiogenesisrelated researches.

Keywords: angiogenesis; DNA chip; duplicate spots, gene expression profile; histone deacetylase

\section{Introduction}

Angiogenesis is an important physiological event known to be related with rheumatoid arthritis, psoriasis, diabetic retinopathy, artery stiffening and inflammation, as well as cancer (Folkman, 1971; Folkman, 1972; Rand, 1981; Colville-Nash and Scott, 1992). A number of genes are known to be involved in the event, including vascular endothelial growth factor (VEGF), basic fibroblast growth factor (bFGF), and matrix metalloproteinases as proangiogenic factors (Schweigerer et al., 1987; Connolly et al., 1989; Haas and Madri, 1999) and von Hippel-Lindau (VHL), thrombospondins, and tissue inhibitor of metalloproteinases (TIMPs) as antiangiogenic factors (Taraboletti et al., 1990; Moses and Langer, 1991; Maxwell et al., 1999). Despite the importance of angiogenesis, researchers have found difficulty to study on a variety of genes related with angiogenesis in a high content way, because DNA chips focusing for angiogenesis have not been developed. DNA chip (microarray) technology has been highlighted as one of powerful ways of genomics study (Shalon et al., 1996). Many fields, including drug discovery and toxicological research, have been benefited from the use of DNA chip technology (Butte, 2002; Kim et al., 2003). However, some short comes in DNA chip technology such as low data reproducibility have to be overcome for better application to genomics study (Kothapalli et al., 2002).

We here report the development of an angiogenesis-focused cDNA chip using PCR products of about 153 angiogenesis-related genes, which consists of two identical blocks. Duplicated spots in the cDNA chip could provide more reliable data than those of conventional DNA chip leading to save the time and cost of the DNA chip experiments. Expression profiles of angiogenesis-focused cDNA chip with human HT1080 fibrosarcoma cells treated with angiogenesis inhibitor/activator were investigated and validated the usefulness of angiogenesis-focused 
cDNA chip for angiogenesis related researches.

\section{Materials and Methods}

\section{Polymerase chain reaction (PCR) of angiogenesis- related genes}

PCR primers for amplification of 153 angiogenesisrelated genes were designed as follow; 1) poly $(A)$ upstream and Alu sequence were eliminated, 2) sequence homology of PCR target regions was minimized, 3) amplicons were $0.2-1 \mathrm{~Kb}$ in size. DNA fragments were amplified from 10 human cDNA Libraries, validated by sequencing, and prepared over $7.2 \mu \mathrm{g}$ per fragment.

\section{Fabrication of angiogenesis cDNA chip}

DNA fragments were spotted duplicate in two blocks by 417 arrayer (Affymetix, Santa Clara, CA) and postprocessed according to the previous report (Schena et al., 1995). Following post-processing, quality controls (QCs) were performed through 3 steps; nonspecific hybridization $Q C$, position hybridization $Q C$, and surface QC. QC-passed angiogenesis DNA chips were stored in a dark dessicator and used for further analysis.

\section{Expression profiling of HT1080 cells}

Human HT1080 fibrosarcoma cells were treated with either $10 \%$ fetal bovine serum (FBS) as angiogenesis activator, or with trichostatin A (TSA) in 10\% FBS as angiogenesis inhibitor for $12 \mathrm{~h}$ following serum starvation for $12 \mathrm{~h}$. HT1080 cells were harvested and total RNAs were isolated. RNA from test groups was labeled with Cy5-dUTP by reverse-transcription and RNA from control groups with Cy3-dUTP. Labeled products were set onto the angiogenesis cDNA chip and incubated at $65^{\circ} \mathrm{C}$ for $16 \mathrm{~h}$ in a dark water-bath. Following wash, scanning by 428 scanner (Affymetrix, Santa Clara, CA), raw data extraction, and statistical analysis using GeneSight data analysis software ver. 3.5 (BioDiscovery, Los Angeles, CA) were achieved.

\section{Signature correlation coefficient value $(\rho)$}

Correlation coefficients between two signatures were calculated using the equation:

$$
\rho=\sum_{k} x_{k} y_{k} /\left(\sum x_{k}^{2} \sum y_{k}^{2}\right)^{1 / 2}
$$

where $x_{k}$ is the $\log _{10}$ of the expression ratio for the $k^{\text {th }}$ gene in the $x$ signature, and $y_{k}$ is the $\log _{10}$ of the expression ratio for the $k^{\text {th }}$ gene in the $y$ signature (Marton et al., 1998).
Table 1. Gene list of Angio_Chip

\begin{tabular}{lcc}
\hline \multicolumn{1}{c}{ Category } & $\begin{array}{c}\text { Total } \\
\text { number }\end{array}$ & Examples \\
\hline $\begin{array}{l}\text { Angiogenesis } \\
\text { activator }\end{array}$ & 87 genes & VEGFs, MMPs, HIF-1 $\alpha$, etc. \\
$\begin{array}{l}\text { Angiogenesis } \\
\text { inhibitor }\end{array}$ & 26 genes & VHL, TIMPs, TSPs, etc. \\
$\begin{array}{l}\text { Oncogene } \\
\begin{array}{l}\text { Tumor } \\
\text { suppressor } \\
\text { Internal } \\
\text { control }\end{array}\end{array}$ & 14 genes & $c-M y c, c-J u n$, ErbB2, etc. \\
\hline
\end{tabular}

\section{Results}

To fabricate angiogenesis-focused cDNA chip (designated as Angio_Chip), we first selected 153 angiogenesis-related genes from GeneBank database (http://www.ncbi.nlm.nih.gov) and Angiogenesis database (http://angiodb.snu.ac.kr). The selected genes were amplified by PCR from 10 human cDNA libraries, including bone marrow, liver, placenta, brain amygdale, brain caudate nucleus, brain cerebellum, brain corpus callosum, brain hippocampus, brain substantia nigra, and brain thalamus (Table 1). The amplified cDNAs were validated through sequencing analysis and were spotted in duplicate onto glass slide by Affymetrix 417 arrayer. Quality controls (QC) of the cDNA chip were performed through 3 steps as described in Materials and Methods.

cDNA chip analysis was performed through the experimental conditions shown in Figure 1. Human fibrosarcoma HT1080 cells were used for this study, because the tumor cell line highly expresses angiogenic factors, such as matrix metalloproteinases and growth factors in response to various stimuli (Morodomi et al., 1992; Mori et al., 1999). These angiogenic factors are essential for the activation of endothelial cells during angiogenesis (Connolly et al., 1989; Haas and Madri, 1999). Two angiogenesis regulators, fetal bovine serum (FBS) and histone deacetylase (HDAC) inhibitor, trichostatin A (TSA), were used to study the gene expression changes in HT1080 cells (Kim et al., 2001).

The validation of the functionality of Angio_Chip was performed through three steps, i.e. scanning image analysis, signature correlation analysis, and microarray data validation using gene expression profiling. In the first step of validation, the scanning image of the examined Angio_Chip was analyzed as shown in Figure 2A. Duplicate spot images of FBS signatures $\left(\mathrm{FBS}^{1 \mathrm{st}}\right.$ and $\mathrm{FBS}^{2 \mathrm{nd}}$ ) were well correlated with each other. Also in TSA signatures, each duplicate image was exactly same. Magnified spots are representative 


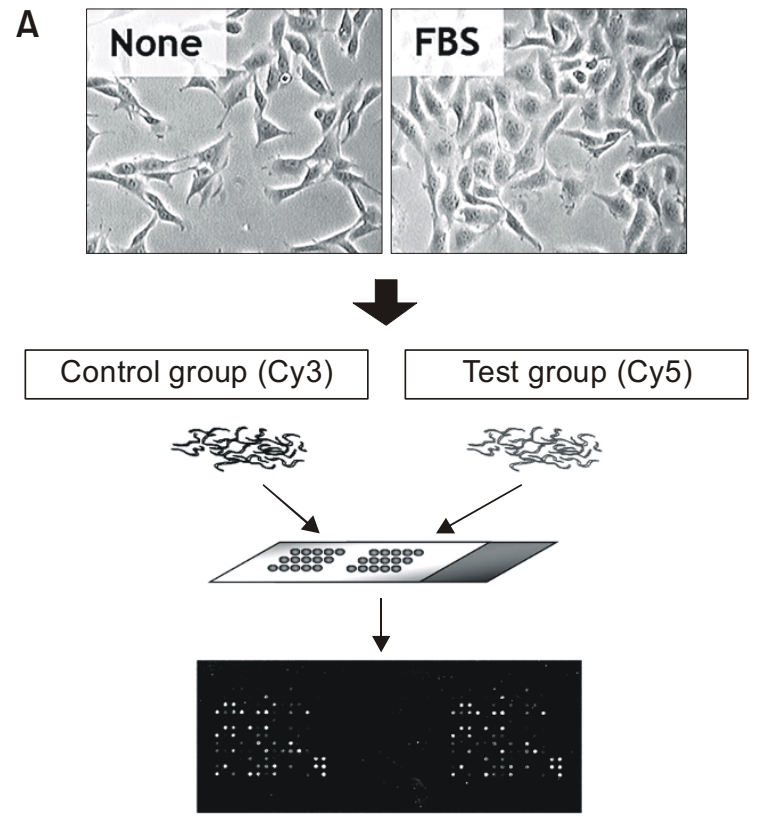

FBS signature

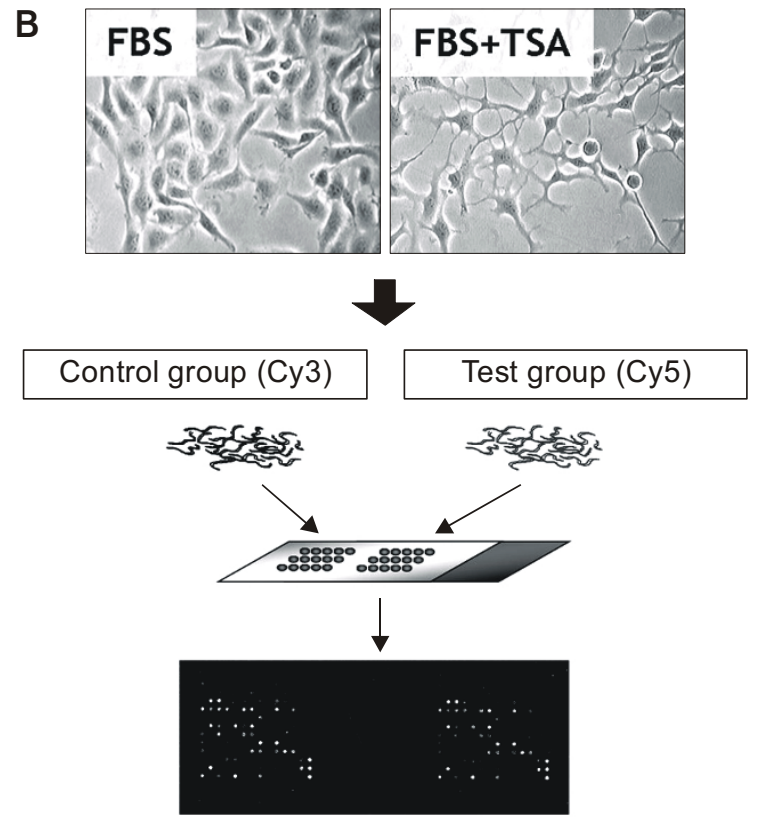

TSA signature

Figure 1. Experimental schemes of cDNA chip analysis. Figures show HT1080 cells treated with indicated reagents and experimental conditions. (A) FBS signature represents CDNA chip data from control (cy3) versus FBS treatment (cy5). (B) TSA signature represents cDNA chip data from FBS treatment (cy3) versus FBS and TSA co-treatment (cy5).

signatures from each experimental condition, which show correlation between each duplicate signature and remarkable difference between two experimental conditions.

In the second step, signature correlation analysis was performed using both hierarchical clustering of gene expression profiles and signature correlation coefficient value $(\rho)$. GeneSight data analysis software (v3.5) was used for hierarchical clustering. As shown in Figure 2B, each duplicate signature in two experimental conditions, $\mathrm{FBS}^{\text {ist }}$ vs $\mathrm{FBS}^{2 \mathrm{2nd}}$ and $\mathrm{TSA}^{\text {1st }}$ vs $T_{S A}{ }^{2 n d}$ were well correlated from the clustering analysis. Signature correlation coefficient value $(\rho)$ has been used for determining a correlation degree between two different gene expression profiles quantitatively (Marton et al., 1998). Signature correlation coefficient values for $\mathrm{FBS}^{1 \text { st }}$ vs $\mathrm{FBS}^{2 \text { nd }}, \mathrm{TSA}^{1 \text { st }}$ vs $\mathrm{TSA}^{2 \mathrm{nd}}$, and $\mathrm{FBS}^{1 \text { st }}$ vs $\mathrm{TSA}^{1 \mathrm{st}}$ were $0.81,0.76$, and $<0.1$, respectively. High correlation values (magnitude of $\rho>0.7 \pm 0.1$ ) are very significantly different from zero, and small correlation values (magnitude of $\rho<0.2)$ are considered as not significant. Each correlation coefficient value was also demonstrated by scatter plot analysis, as shown in Figure 2C. Highly correlated signatures were shown as spots forming a diagonal line.

In the third step of validation, gene expression data were analyzed and compared with previously reported data. Among 153 angiogenesis related genes, 7
Table 2. Gene expression profiles in response to TSA.

\begin{tabular}{|c|c|c|c|}
\hline \multicolumn{2}{|c|}{ Up-regulated genes by TSA } & \multicolumn{2}{|c|}{ Down-regulated genes by TSA } \\
\hline Gene name & $\begin{array}{c}\text { Ratio } \\
\left(\log _{2} \text { cy5/cy3) }\right.\end{array}$ & Gene name & $\begin{array}{c}\text { Ratio } \\
\left(\log _{2} \text { cy5/cy3) }\right.\end{array}$ \\
\hline plakoglobin & 1.4 & HDAC 7B & -2.0 \\
\hline STAT3 & 1.3 & IL-1 $\beta$ & -1.5 \\
\hline TSP-1 & 1.3 & bFGF & -1.4 \\
\hline HDAC 3 & 1.2 & Flt1 & -1.1 \\
\hline p21, INK1A & 1.1 & UPAR & -0.8 \\
\hline INK3 & 1.1 & VEGF C & -0.8 \\
\hline TSP-2 & 1.1 & - & - \\
\hline
\end{tabular}

were selected as up-regulated genes and 6 were down-regulated genes in response to TSA (Table 2). The selected genes were further validated using RT-PCR analysis (Figure 3 ). Among the selected up-regulated genes, junction plakoglobin and p21 WAF1 are well known HDAC target genes (Hassig et al., 1997; Shim et al., 2004). Thrombospondin 1 (TSP-1) has been reported recently as an HDAC target gene (Cinatl et al., 2002). In the down-regulated genes, VEGFs are known to be decreased by HDAC inhibitors (Kim et al., 2001; Deroanne et al., 2002). In addition, Flt1 and UPAR were reported to be down regulated by a depsipeptide HDAC inhibitor, FK228 
A

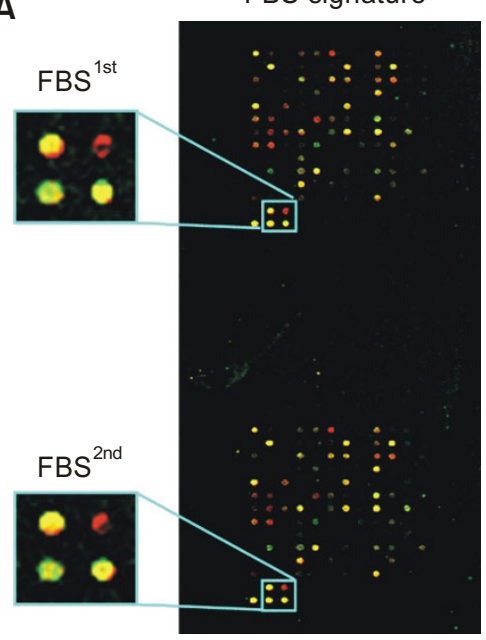

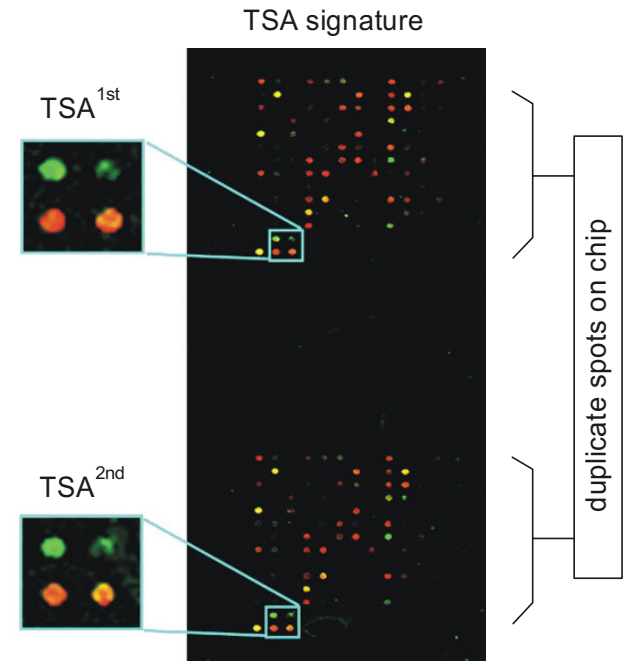

B
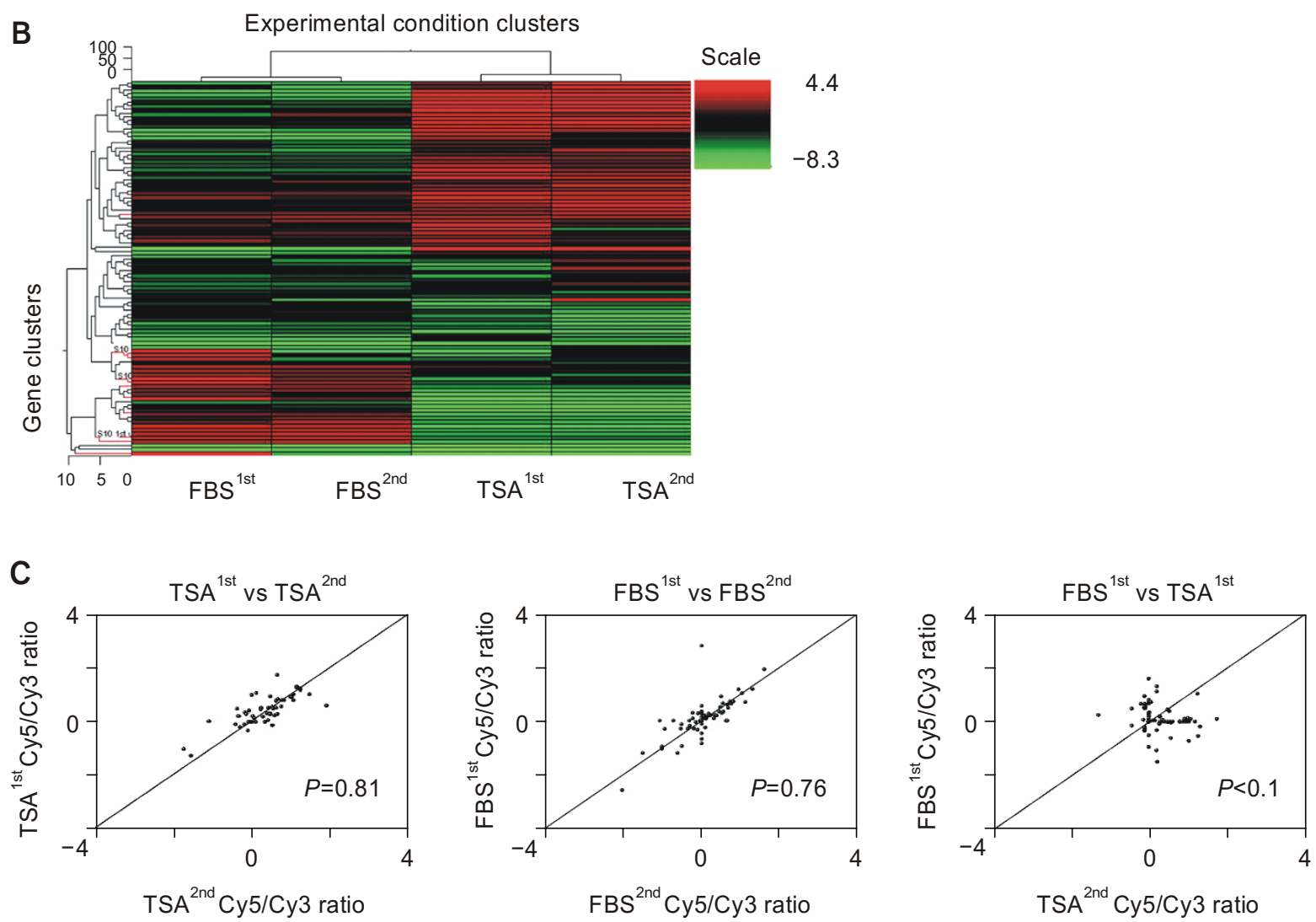

Figure 2. Microarray data validation. (A) Scanning image analysis of cDNA chip data. Duplicate microarray images from each experimental condition (FBS and TSA) are shown. Left panel; scanning image of FBS signature. Each duplicate signature is designated as $\mathrm{FBS}^{1 \mathrm{st}}$ and $\mathrm{FBS}^{2 \mathrm{nd}}$. Magnified images are representative spots in each duplicate. Right panel; duplicate scanning images from TSA signature. (B) Hierarchical clustering of each duplicate signature in two experimental conditions is shown. (C) Scatter plots and signature correlation coefficient values $(\rho)$ of each duplicate signature (left and middle panels). The right panel represents the signature correlation coefficient value $(\rho)$ between two experimental conditions (FBS vs TSA). 


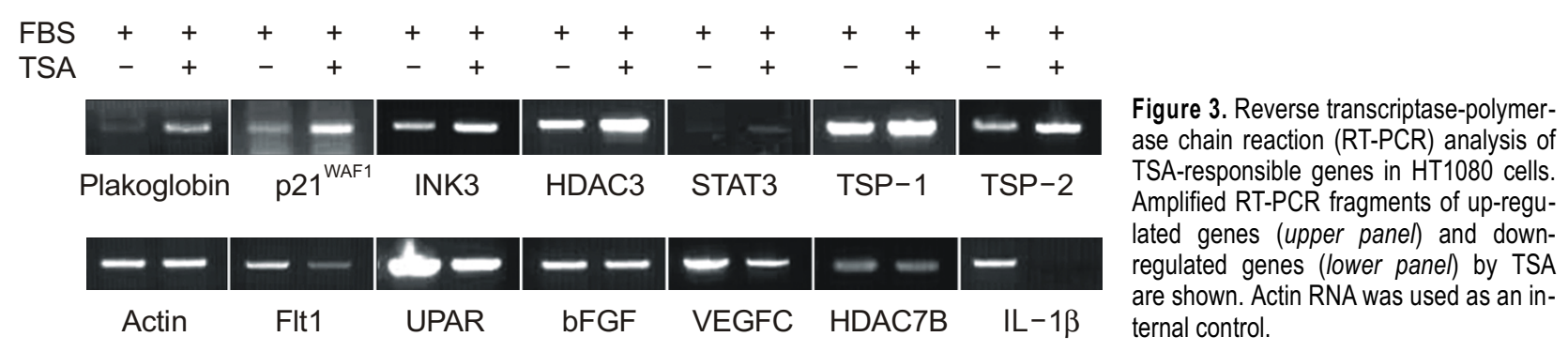

(Kwon et al., 2002). These results demonstrate that the gene expression profiles of several known HDAC target genes in Angio_Chip are well correlated with the previously reported data.

\section{Discussion}

The present study shows the development of the first angiogenesis-focused cDNA chip with duplicated spots. The genes arrayed on the Angio_Chip are fully listed on the web (http://rnd.takara.co.kr). Arrayed genes are all known genes involved in angiogenesis. Notably, angiogenesis-related genes which have been recently focused by many of scientists were selected. Conventional genome-wide DNA chips are very informative and provide a vast of gene expression information. However, this complicated genomic information often turn to be useless, if they are not analyzed adequately for specific research purposes. Alternatively, some of phenotype or disease-focused DNA chips, such as Cancer genefocused DNA chip, are very useful, because a small number of genes can provide the accurate and reproducible data (Kim et al., 2002; Shim et al., 2004). Moreover, Angio_Chip has duplicate spots on a slide which can provide more reliable data from DNA microarray analyses. From the validation experiments, all duplicate signatures in Angio_Chip are well correlated with each other demonstrating that the duplicate spots on the chip are very effective to generate reproducible data from DNA microarray analyses. We finally examined whether the microarray data are consistent with previously reported results. The data sets from TSA signature were used for this study, because HDAC is a well known direct transcriptional regulator and many of its target genes have been reported (Hoshikawa et al., 1994; Grunstein, 1997). Some known HDAC target genes are also detected in the microarray data and the expression profiles of the genes are well correlated with previously reported data. Several other genes were also regulated in their gene expression by TSA but these have not been reported yet. Further studies on these new HDAC target genes would be important for deciphering new roles of HDAC in angiogenesis.

In conclusion, the present study demonstrates that the Angio_Chip is a functional DNA chip, which will be very useful tool for angiogenesis-related basic and applied studies.

\section{Acknowledgement}

This work was supported by the National Research Laboratory Grant from the Ministry of Science and Technology, the Grant from Small and Medium Business Administration, Republic of Korea and the Brain Korea 21 Project.

\section{References}

Butte A. The use and analysis of microarray data. Nat Rev Drug Discov 2002;1:951-60

Cinatl J Jr, Kotchetkov R, Blaheta R, Driever PH, Vogel JU, Cinatl J. Induction of differentiation and suppression of malignant phenotype of human neuroblastoma $B E(2)-C$ cells by valproic acid: enhancement by combination with interferonalpha. Int J Oncol 2002;20:97-106

Colville-Nash PR, Scott DL. Angiogenesis and rheumatoid arthritis: pathogenic and therapeutic implications. Ann Rheum Dis 1992;51:919-25

Connolly DT, Heuvelman DM, Nelson R, Olander JV, Eppley BL, Delfino JJ, Siegel NR, Leimgruber RM, Feder J. Tumor vascular permeability factor stimulates endothelial cell growth and angiogenesis. J Clin Invest 1989;84:1470-8

Deroanne CF, Bonjean K, Servotte S, Devy L, Colige A, Clausse N, Blacher S, Verdin E, Foidart JM, Nusgens BV, Castronovo V. Histone deacetylases inhibitors as antiangiogenic agents altering vascular endothelial growth factor signaling. Oncogene 2002;21:427-36

Folkman J. Tumor angiogenesis: therapeutic implications. $\mathrm{N}$ Engl J Med 1971;285:1182-6

Folkman J. Angiogenesis in psoriasis: therapeutic implications. J Invest Dermatol 1972;59:40-3

Grunstein M. Histone acetylation in chromatin structure and transcription. Nature 1997;389:349-52

Haas TL, Madri JA. Extracellular matrix-driven matrix metalloproteinase production in endothelial cells: implications for 
angiogenesis. Trends Cardiovasc Med 1999;9:70-7

Hassig CA, Tong JK, Schreiber SL. Fiber-derived butyrate and the prevention of colon cancer. Chem Biol 1997;4:783-9

Hoshikawa Y, Kwon HJ, Yoshida M, Horinouchi S, Beppu T. Trichostatin A induces morphological changes and gelsolin expression by inhibiting histone deacetylase in human carcinoma cell lines. Exp Cell Res 1994;214:189-97

Kim JH, Shim JS, Lee SK, Kim KW, Rha SY, Chung HC, Kwon HJ. Microarray-based analysis of anti-angiogenic activity of demethoxycurcumin on human umbilical vein endothelial cells: crucial involvement of the down-regulation of matrix metalloproteinase. Jpn J Cancer Res 2002;93: 1378-85

Kim JR, Lee SR, Chung HJ, Kim S, Baek SH, Kim JH, Kim YS. Identification of amyloid beta-peptide responsive genes by cDNAmicroarray technology: Involvement of RTP801 in amyloid beta-peptide toxicity. Exp Mol Med 2003;35:403-11

Kim MS, Kwon HJ, Lee YM, Baek JH, Jang JE, Lee SW, Moon EJ, Kim HS, Lee SK, Chung HY, Kim CW, Kim KW. Histone deacetylases induce angiogenesis by negative regulation of tumor suppressor genes. Nat Med 2001;7: 437-43

Kim YH, Lee JH, Lim DS, Shim WJ, Ro YM, Park GH, Becker KG, Cho-Chung YS, Kim MK. Gene expression profiling of oxidative stress on atrialfibrillation in humans. Exp Mol Med 2003; 35:336-49

Kothapalli R, Yoder SJ, Mane S, Loughran TP Jr. Microarray results: how accurate are they? BMC Bioinformatics 2002; $3: 22$

Kwon HJ, Kim MS, Kim MJ, Nakajima H, Kim KW. Histone deacetylase inhibitor FK228 inhibits tumor angiogenesis. Int J Cancer 2002;97:290-6

Marton MJ, DeRisi JL, Bennett HA, lyer VR, Meyer MR, Roberts CJ, Stoughton R, Burchard J, Slade D, Dai H, Bassett DE Jr, Hartwell LH, Brown PO, Friend SH. Drug target validation and identification of secondary drug target effects using DNA microarrays. Nat Med 1998;4:1293-301
Maxwell PH, Wiesener MS, Chang GW, Clifford SC, Vaux EC, Cockman ME, Wykoff CC, Pugh CW, Maher ER, Ratcliffe PJ. The tumour suppressor protein VHL targets hypoxia-inducible factors for oxygen-dependent proteolysis. Nature 1999;399:271-5

Mori A, Arii S, Furutani M, Hanaki K, Takeda Y, Moriga T, Kondo Y, Gorrin Rivas MJ, Imamura M. Vascular endothelial growth factor-induced tumor angiogenesis and tumorigenicity in relation to metastasis in a HT1080 human fibrosarcoma cell model. Int J Cancer 1999;80:738-43

Morodomi T, Ogata Y, Sasaguri Y, Morimatsu M, Nagase $\mathrm{H}$. Purification and characterization of matrix metalloproteinase 9 from U937 monocytic leukaemia and HT1080 fibrosarcoma cells. Biochem J 1992;285( Pt 2):603-11

Moses MA, Langer R. A metalloproteinase inhibitor as an inhibitor of neovascularization. J Cell Biochem 1991;47: 230-5

Rand LI. Recent advances in diabetic retinopathy. Am J Med 1981;70:595-602

Schena M, Shalon D, Davis RW, Brown PO. Quantitative monitoring of gene expression patterns with a complementary DNA microarray. Science 1995;270:467-70

Schweigerer L, Neufeld G, Friedman J, Abraham JA, Fiddes JC, Gospodarowicz D. Capillary endothelial cells express basic fibroblast growth factor, a mitogen that promotes their own growth. Nature 1987;325:257-9

Shalon D, Smith SJ, Brown PO. A DNA microarray system for analyzing complex DNA samples using two-color fluorescent probe hybridization. Genome Res 1996;6:639-45

Shim JS, Kim DH, Kwon HJ. Plakoglobin is a new target gene of histone deacetylase in human fibrosarcoma HT1080 cells. Oncogene 2004;23:1704-11

Taraboletti G, Roberts D, Liotta LA, Giavazzi R. Platelet thrombospondin modulates endothelial cell adhesion, motility, and growth: a potential angiogenesis regulatory factor. $\mathrm{J}$ Cell Biol 1990;111:765-72 